\title{
A Survey on the Current Status of Neonatal Physical Therapy in South Korea
}

\author{
Sung Tae Kim¹, Joon-Hee Lee ${ }^{2}$ \\ 'Department of Physical Therapy, Chungbuk National University Hospital, Cheongju; ${ }^{2}$ Department of Physical Therapy, College of Health and \\ Medical Science, Cheongju University, Cheongju, Korea
}

Purpose: This study aimed to investigate and report the current status of physical therapy (PT) performed in Korean neonatal intensive care units (NICU) to present foundational data that promotes the advances in neonatal PT in Korea.

Methods: Based on the Health Insurance Review and Assessment (HIRA) data, we administered a questionnaire survey to 74 hospitals (39 tertiary and 35 general hospitals) in Korea equipped with a NICU and pediatric PT unit. We developed a 32-item questionnaire with reference to previous Korean studies. The questionnaires were distributed and retrieved via regular mail and an online system.

Results: Of the 74 hospitals, 58 (78\%) practiced neonatal PT and the duration of each session significantly differed according to the hospital rating. PT was given, depending on clinical symptoms, to infants who were preterm and low birth-weight (96.5\%), had brain and spinal cord diseases (84.5\%), had pathological tonus (94.8\%), with respiratory problems $(65.5 \%)$, for range of motion exercises $(82.8 \%)$, for neurodevelopment approaches (72.4\%), and for positioning (70.7\%). Interdisciplinary meetings were held to share clinical decisionmaking in $17.2 \%$ of the hospitals surveyed and parent-participating education to ensure a family-centered approach was offered in $63.8 \%$ of the hospitals. The barriers of neonatal PT included low insurance fees, insufficient awareness of colleagues, and the severity of the patient.

Conclusion: This study is the first report of the current status of neonatal PT in Korea. The findings of this study will serve as foundational data to review the current neonatal PT practice and promote further advances.

Keywords: Neonatal intensive care units, Neonatal physical therapy, Pediatric physical therapy, South Korea, Survey

\section{INTRODUCTION}

The neonatal intensive care unit (NICU) is a medical unit specializing in the comprehensive treatment and care of infants at high risk to promote their neonatal survival and post-survival life. ${ }^{1}$ Among neonates aged 28 days or under, infants are admitted to the NICU due to congenital deformities that require surgical treatment or severe illnesses such as sepsis, as well as preterm (gestation age $<37$ weeks) and low birth weight infants (birth weight, $<2,500 \mathrm{~g}$ ). ${ }^{2}$ As critically ill infants often have problems that may lead to a disability, including muscle tone abnormalities, myoparalysis, joint contracture, or overall growth and development issues, or clinical symptoms linked to survival, for example swallowing disorders or respiratory problems due to immature lungs, rehabilitation to manage

Received Jun 4, 2020 Revised Jun 10, 2020

Accepted Jun 11, 2020

Corresponding author Joon-Hee Lee

E-mail pieta2000@hanmail.net these conditions are essential. ${ }^{3}$

The Ministry of Health and Welfare launched the "NICU Support Project" in 2008 and has strived to expand the number of NICU beds and various infrastructures for the treatment and management of high-risk infants. As a result, the survival rate of very low birth weight infants rapidly increased to $84.8 \%$ in 2013-2014, a level comparable to that of more developed countries. ${ }^{4}$ Infants discharged after an acute phase of treatment require regular follow-ups due to the increased risk of developmental delays, even after survival. Traditionally, neonatal intensive care has focused on infant survival but currently, the emphasis has been shifted to a patient "quality of survival" due to the elevated survival rate. ${ }^{5}$ According to a statistical report by the Health Insurance Review and Assessment (HIRA), the number of infants at high risk who were diagnosed

Copylight (C2020 The Korean Society of Physical Therapy

This is an Open Access article distribute under the terms of the Creative Commons Attribution Non-commercial License (https:// creativecommons.org/license/by-nc/4.o.) which permits unrestricted non-commercial use, distribution, and reproduction in any medium, provided the original work is properly cited. 
with code R62 (other lack of expected normal physiological development) tripled from 16,690 in 2010 to 54,295 in $2018 .{ }^{6}$ To manage developmental problems that manifest during the neonatal stage, there are inevitable demands for a neonatal rehabilitation team, comprising of experts from various disciplines. ${ }^{7}$ Neonatal rehabilitation experts take a comprehensive approach to care for infants, understanding the stress faced by parents and considering various medical and environmental factors that may impact infants and their families. ${ }^{8}$

Neonatal physical therapy (PT) is a field of rehabilitation that provides interventions to infants at high risk who are admitted to the NICU. In the United States, regional NICUs were established in the 1970s and have served to improve infants' respiratory functions. ${ }^{8}$ Currently, physical therapists in the NICU serve as experts to improve physical functions, perform clinical evaluations, and administer interventions to minimize neurodevelopmental disorders, maintain and manage musculoskeletal function, and improve respiratory function. ${ }^{3}$ With the NICU system becoming more systematic and advanced, there is a growing emphasis on the role of neonatal physical therapists as experts to minimize problems that hinder neurodevelopmental and musculoskeletal growth and to provide emotional support along with appropriate education to parents in stressful situations. Active discussions are currently underway to establish theoretical guidelines for this purpose.

On the other hand, theoretical studies that examine the roles and current work scope of physical therapists in the NICU in Korea are currently lacking, which prevents the establishment of a standard for the role of physical therapists as rehabilitation experts in the NICU and achieving a higher level of education and work proficiency. Therefore, this study aims to 1) report the current practice of neonatal physical therapy in healthcare institutions in Korea that are equipped with a NICU and pediatric PT unit and 2) based on these results, discuss the roles of neonatal physical therapists and future advances in Korea.

\section{METHODS}

\section{Subjects}

We identified healthcare facilities equipped with a NICU nationwide using data from the HIRA. Of the 92 healthcare facilities nationwide (42 tertiary and 50 general), 74 (39 tertiary and 35 general) hospitals equipped with an exclusive area and facility for pediatric patients and a pediatric PT unit with full-time pediatric physical therapists were identified and enrolled in the study.

\section{Procedure}

Questionnaires were distributed to each hospital after obtaining consent over the phone. Questionnaires were distributed and retrieved via mail or an online questionnaire (Google form) from September to November 2019.

\section{Development of questionnaire items}

The questionnaire items were developed and modified with reference to previous studies in Canada, Australia, and Korea. ${ }^{7,10-12}$ The finalized questionnaire consisted of 3 sections. The cover explained the purpose, structure, filling out, and retrieval of the questionnaire. A flow chart was used to instruct those who are currently performing PT in the NICU to complete all 3 sections and those who are not to complete only sections 1 and 3 . Section 1 consisted of regarding participants' demographics. Section 2 consisted of regarding the practice of PT in the NICU. Section 3 consisted of the limitations and suggestions. The validity of the content was reviewed by 4 pediatric physical therapists with more than 10 years of experience and a physical therapy professor.

\section{Data analysis}

The collected data were coded in a Microsoft Excel spreadsheet and analyzed using SPSS Ver. 22.0. The general characteristics of the research institute are represented by the median and range, and the difference between the Tertiary hospital and the general hospital was tested by independent $t$ test for the average value. The contents were analyzed using frequently analysis and are presented as frequency and percentage. Differences in the responses between tertiary hospitals and general hospitals were analyzed with chi-square tests (or Fisher's Exact Test). The significance level of the statistics was set at 0.05 .

\section{RESULTS}

\section{General characteristics of the study hospitals}

The median (range) of the total number of hospital beds was statistically significant $(\mathrm{p}<0.05)$ between groups, with 1,004 $(639-2,937)$ 
Table 1. Demographic characteristics of neonatal physical therapists

\begin{tabular}{|c|c|c|c|c|c|}
\hline Question & Answer & $\begin{array}{c}\text { Total } \\
(n=74)\end{array}$ & $\begin{array}{l}\text { Tertiary } \\
(n=39)\end{array}$ & $\begin{array}{c}\text { General } \\
(n=35)\end{array}$ & $\begin{array}{l}\mathrm{p} \text {-value } \\
\left(\chi^{2} \text {-test }\right)\end{array}$ \\
\hline \multirow[t]{2}{*}{ Sex } & Female & $58.1 \%(43)$ & $56.4 \%(22)$ & $60 \%(21)$ & \\
\hline & Male & $41.9 \%(31)$ & $43.6 \%(17)$ & $40 \%(14)$ & \\
\hline Work experience & Less than $2 \mathrm{yr}$ & $16.2 \%(12)$ & $15.4 \%(6)$ & $17.1 \%(6)$ & \\
\hline \multirow[t]{2}{*}{ (pediatric PT) } & $3-6 \mathrm{yr}$ & $20.3 \%(15)$ & $20.5 \%(8)$ & $20 \%(7)$ & \\
\hline & 7 yr or more & $63.5 \%(47)$ & $64.1 \%(25)$ & $62.9 \%(22)$ & \\
\hline \multirow[t]{4}{*}{ Highest education level } & Associate degree & $2.7 \%(2)$ & $5.1 \%(2)$ & $0 \%(0)$ & \\
\hline & Bachelor & $45.9 \%(34)$ & $44.6 \%(17)$ & $48.6 \%(17)$ & \\
\hline & Master & $47.3 \%(35)$ & $46.2 \%(18)$ & $48.6 \%(17)$ & \\
\hline & $\mathrm{PhD}$ & $4.1 \%(3)$ & $5.1 \%(2)$ & $2.9 \%(1)$ & \\
\hline \multirow[t]{2}{*}{ Administering neonatal PT } & Yes & $78.38 \%(58)$ & $94.9 \%(37)$ & $60 \%(21)$ & 0.001 * \\
\hline & No & $21.62 \%(16)$ & $5.1 \%(2)$ & $40 \%(14)$ & \\
\hline
\end{tabular}

Non continuity variables are expressed ratio (frequency).

PT: Physical therapy or physical therapist.

${ }^{*} p=<0.05$

Table 2. Neonatal PT work allocation

\begin{tabular}{|c|c|c|c|c|c|}
\hline Question & Answer & Total $(N=58)$ & Tertiary $(\mathrm{N}=37)$ & General $(N=21)$ & p-value $\left(x^{2}\right.$-test \\
\hline \multirow{5}{*}{ Number of employees in pediatric PT unit } & 1 & $29.3 \%(17)$ & $27.0 \%(10)$ & $33.3 \%(7)$ & \\
\hline & 2 & $32.8 \%(19)$ & $29.7 \%(11)$ & $38.1 \%(8)$ & \\
\hline & 3 & $13.8 \%(8)$ & $16.2 \%(6)$ & $9.5 \%(2)$ & \\
\hline & 4 & $5.2 \%(3)$ & $8.1 \%(3)$ & $0 \%(0)$ & \\
\hline & $\geq 5$ & $19 \%(11)$ & $18.9 \%(7)$ & $19.0 \%(4)$ & \\
\hline \multirow[t]{5}{*}{ Number of neonatal PT } & 1 & $55.2 \%(32)$ & $54.1 \%(20)$ & $57.1 \%(12)$ & \\
\hline & 2 & $27.6 \%(16)$ & $27.0 \%(10)$ & $28.6 \%(6)$ & \\
\hline & 3 & $13.8 \%(8)$ & $13.5 \%(5)$ & $14.3 \%(3)$ & \\
\hline & 4 & $3.4 \%(2)$ & $5.4 \%(2)$ & $0 \%(0)$ & \\
\hline & $>5$ & $0 \%(0)$ & $0 \%(0)$ & $0 \%(0)$ & \\
\hline \multirow[t]{5}{*}{ Allocation time for neonatal PT (per week) } & $\leq 5 \mathrm{hr}$ & $89.7 \%(52)$ & $83.8 \%(31)$ & $100 \%(21)$ & \\
\hline & $6-10 \mathrm{hr}$ & $6.9 \%(4)$ & $10.8 \%(4)$ & $0 \%(0)$ & \\
\hline & $11-20 \mathrm{hr}$ & $0 \%(0)$ & $0 \%(0)$ & $0 \%(0)$ & \\
\hline & $21-30 \mathrm{hr}$ & $1.7 \%(1)$ & $2.7 \%(1)$ & $0 \%(0)$ & \\
\hline & $31-40 \mathrm{hr}$ & $1.7 \%(1)$ & $2.7 \%(1)$ & $0 \%(0)$ & \\
\hline \multirow[t]{4}{*}{ Allocation time of neonatal PT (per session) } & $\leq 10 \min$ & $36.2 \%(21)$ & $24.3 \%(9)$ & $57.1 \%(12)$ & $0.023^{*}$ \\
\hline & $\leq 20 \min$ & $32.8 \%(19)$ & $43.3 \%(16)$ & $14.3 \%(3)$ & \\
\hline & $\leq 30 \min$ & $29.3 \%(17)$ & $32.4 \%(12)$ & $23.8 \%(5)$ & \\
\hline & $\geq 40 \min$ & $1.7 \%(1)$ & $0 \%(0)$ & $4.8 \%(1)$ & \\
\hline \multirow[t]{5}{*}{ Number of neonatal PT sessions (per week) } & Everyday & $53.4 \%(31)$ & $45.9 \%(17)$ & $66.7 \%(14)$ & \\
\hline & 3 times a week & $10.3 \%(6)$ & $10.8 \%(4)$ & $9.5 \%(2)$ & \\
\hline & Twice a week & $6.9 \%(4)$ & $10.8 \%(4)$ & $0 \%(0)$ & \\
\hline & Once a week & $5.2 \%(3)$ & $5.4 \%(2)$ & $4.8 \%(1)$ & \\
\hline & Non-regular & $24.1 \%(14)$ & $27.0 \%(10)$ & $19.0 \%(4)$ & \\
\hline \multirow[t]{4}{*}{ Number of neonatal PT patients (per week) } & $\leq 5$ & $81.0 \%(47)$ & $78.4 \%(29)$ & $85.7 \%(18)$ & \\
\hline & 6-10 people & $12.1 \%(7)$ & $13.5 \%(5)$ & $9.5 \%(2)$ & \\
\hline & 11-20 people & $3.4 \%(2)$ & $2.7 \%(1)$ & $4.8 \%(1)$ & \\
\hline & 21-30 people & $3.4 \%(2)$ & $5.4 \%(2)$ & $0 \%(0)$ & \\
\hline
\end{tabular}

Non continuity variables are expressed ratio (frequency).

PT: Physical therapy or physical therapist.

${ }^{*} \mathrm{p}=<0.05$ 
for the Tertiary hospital and $720(345-1,056)$ for the general hospital. The number of NICU beds was statistically significant $(\mathrm{p}<0.05)$ between the groups, with 25 (6-60) for the Tertiary hospital and 15 (240) for the general hospital. On the other hand, there were no differences in the number of full-time physical therapists: 14 (5-53) for Tertiary hospitals and 12 (3-29) for general hospitals ( $\mathrm{p}>0.05)$.

\section{Demographic characteristics of neonatal physical therapists}

Table 1 shows the demographic characteristics of the participants. Most of the participants had 7 years or more experience in pediatric physical therapy. More than half of the participants had a master's degree or Ph.D. 58 of the 74 hospitals (78.38\%) were currently performing neonatal PT, with a statistically significant difference in this per- centage between tertiary hospitals and general hospitals $(\mathrm{p}<0.05)$.

\section{Neonatal PT work allocation}

Table 2 shows the current status of neonatal PT. The majority of tertiary and general hospitals had fewer than 2 employees working in their pediatric PT unit (62.1\%), and 55.2\% had only 1 physical therapist in charge of neonatal PT. The duration of PT work in the NICU tended to be less than 5 hours per week (89.7\%). In a given week, most physical therapists performed PT on fewer than 5 patients (81\%). The most common duration per neonatal PT session was "less than 10 minutes" (57.1\%) in general hospitals and "less than 20 minutes" (43.3\%) in tertiary hospitals, showing a significant difference between the types of hospitals $(\mathrm{p}<0.05)$.

Table 3. Diseases, symptoms, evaluation and intervention

\begin{tabular}{|c|c|c|c|c|c|}
\hline Question & Answer & $\begin{array}{c}\text { Total } \\
(\mathrm{N}=58)\end{array}$ & $\begin{array}{l}\text { Tertiary } \\
(\mathrm{N}=37)\end{array}$ & $\begin{array}{l}\text { General } \\
(\mathrm{N}=21)\end{array}$ & $\begin{array}{l}\text { p-value } \\
\left(\chi^{2} \text {-test }\right)\end{array}$ \\
\hline \multirow[t]{6}{*}{ Patient's disease } & Premature & $96.5 \%(55)$ & $94.4 \%(34)$ & $100 \%(21)$ & \\
\hline & Brain and spinal cord & $84.5 \%(49)$ & $89.2 \%(33)$ & $76.2 \%(16)$ & \\
\hline & Heart and respiratory & $37.9 \%(22)$ & $40.5 \%(15)$ & $33.3 \%(7)$ & \\
\hline & Genetic & $32.8 \%(19)$ & $35.1 \%(13)$ & $28.6 \%(6)$ & \\
\hline & Muscular dystrophy & $20.7 \%(12)$ & $24.3 \%(9)$ & $14.3 \%(3)$ & \\
\hline & Musculoskeletal & $8.6 \%(5)$ & $10.8 \%(4)$ & $4.8 \%(1)$ & \\
\hline \multirow[t]{6}{*}{ Clinical symptoms } & Pathological tonus & $94.8 \%(55)$ & $94.6 \%(35)$ & $95.2 \%(20)$ & \\
\hline & Respiratory problems & $65.5 \%(38)$ & $70.3 \%(26)$ & $57.1 \%(12)$ & \\
\hline & Developmental problems & $58.6 \%(34)$ & $54.1 \%(20)$ & $66.7 \%(14)$ & \\
\hline & Swallowing problem & $48.3 \%(28)$ & $48.6 \%(18)$ & $47.6 \%(10)$ & \\
\hline & Joint contracture & $43.1 \%(25)$ & $43.2 \%(16)$ & $42.9 \%(9)$ & \\
\hline & Muscle paralysis & $34.5 \%(20)$ & $32.4 \%(12)$ & $38.1 \%(8)$ & \\
\hline \multirow[t]{4}{*}{ Participants in neonatal physical therapy } & PT alone & $77.6 \%(45)$ & $81.1 \%(30)$ & $71.4 \%(15)$ & \\
\hline & PT and parents & $10.3 \%(6)$ & $5.4 \%(2)$ & $19.0 \%(4)$ & \\
\hline & PT and nurse & $8.6 \%(5)$ & $8.1 \%(3)$ & $9.5 \%(2)$ & \\
\hline & PT, parents, and nurse & $3.4 \%(2)$ & $5.4 \%(2)$ & $0 \%(0)$ & \\
\hline \multirow[t]{3}{*}{ Evaluation Form } & Did not perform & $50.0 \%(29)$ & $54.1 \%(20)$ & $42.9 \%(9)$ & \\
\hline & Based on own criteria & $50.0 \%(29)$ & $51.4 \%(19)$ & $47.6 \%(10)$ & \\
\hline & Standard evaluation tool & $8.5 \%(5)$ & $5.4 \%(2)$ & $14.3 \%(3)$ & \\
\hline \multirow[t]{10}{*}{ Intervention } & Range of motion & $82.8 \%(48)$ & $81.1 \%(30)$ & $85.7 \%(18)$ & \\
\hline & Neurodevelopmental approach & $72.4 \%(42)$ & $73.0 \%(27)$ & $71.4 \%(15)$ & \\
\hline & Positioning & $70.7 \%(41)$ & $73.0 \%(27)$ & $66.7 \%(14)$ & \\
\hline & Cardio-respiratory PT & $29.3 \%(17)$ & $29.7 \%(11)$ & $28.6 \%(6)$ & \\
\hline & Family centered approach & $27.6 \%(16)$ & $29.7 \%(11)$ & $23.8 \%(5)$ & \\
\hline & Feeding and swallowing & $17.2 \%(10)$ & $16.2 \%(6)$ & $19.0 \%(4)$ & \\
\hline & Environmental modifications & $13.8 \%(8)$ & $13.5 \%(5)$ & $14.3 \%(3)$ & \\
\hline & Sensory integration & $10.3 \%(6)$ & $5.4 \%(2)$ & $19.0 \%(4)$ & \\
\hline & Splinting & $3.4 \%(2)$ & $5.4 \%(2)$ & $0 \%(0)$ & \\
\hline & Handling & $1.7 \%(1)$ & $2.7 \%(1)$ & $0 \%(0)$ & \\
\hline
\end{tabular}

Non continuity variables are expressed ratio (frequency).

PT: Physical therapy or Physical therapist. 


\section{Diseases, symptoms, evaluations and interventions}

Table 3 shows the evaluation and intervention for infants receiving PT. The most common condition among neonates in the NICU was preterm and low birth-weight birth (96.5\%), followed by brain and spinal cord disease (84.5\%), and heart and respiratory disease (37.9\%). The most common clinical symptoms were pathological tonus (94.8\%), followed by respiratory problems (65.5\%), and developmental problems (58.6\%). The majority (77.6\%) of the participants stated that they perform neonatal PT alone. Half (50\%) of participants do not perform patient evaluation during neonatal PT, and the other half (50\%) generally performed evaluations based on their own criteria, as opposed to using a standardized evaluation tool. The most common neonatal PT interventions were range of motion exercise $(82.8 \%)$, a neurodevelopmental approach (72.4\%), and positioning $(70.7 \%)$.

\section{Team approach and parent education}

Table 4 shows the team approaches and parental education current- ly in place for neonatal rehabilitation. In addition to physical therapists, other common professions included in the neonatal rehabilitation team included a rehabilitation physician, pediatricians, NICU nurses, and occupational therapists. Interdisciplinary meetings for the sharing of clinical decision-making were only performed in $17.2 \%$ (10 hospitals) of the hospitals. In particular, while clinical decision-making was shared with NICU nurses in tertiary hospitals, it was not shared with nurses in general hospitals $(\mathrm{p}<0.05)$. Parent education was given in $63.8 \%$ (37 hospitals) of the hospitals, primarily through 1:1 in person education.

\section{Limitations of current neonatal PT and suggestions}

Table 5 shows the limitations and suggestions for PT in the NICU. A total of $48.6 \%$ of the participants pinpointed insufficient awareness of colleagues' as a barrier to promoting neonatal PT. In relation to this, $62.2 \%$ of the participants responded the awareness of needs by colleagues' to facilitate neonatal PT. While $43.4 \%$ of the participants claimed to have plans to promote neonatal PT, 56.8\% said

Table 4. Team approaches and parental education

\begin{tabular}{|c|c|c|c|c|c|}
\hline Question & Answer & $\begin{array}{c}\text { Total } \\
(\mathrm{N}=58)\end{array}$ & $\begin{array}{c}\text { Tertiary } \\
(\mathrm{N}=37)\end{array}$ & $\begin{array}{l}\text { General } \\
(\mathrm{N}=21)\end{array}$ & $\begin{array}{l}\text { P-value } \\
\left(\chi^{2} \text {-test) }\right.\end{array}$ \\
\hline \multirow[t]{7}{*}{ Rehabilitation team members } & Rehabilitation physician & $75.9 \%(44)$ & $83.8 \%(31)$ & $61.9 \%(13)$ & \\
\hline & Pediatrician & $67.2 \%(39)$ & $73.0 \%(27)$ & $57.1 \%(12)$ & \\
\hline & NIUC nurse & $58.6 \%(34)$ & $64.9 \%(24)$ & $47.6 \%(10)$ & \\
\hline & OT & $50.0 \%(29)$ & $51.4 \%(19)$ & $47.6 \%(10)$ & \\
\hline & SLT & $3.4 \%(2)$ & $5.4 \%(2)$ & $0 \%(0)$ & \\
\hline & Social worker & $1.7 \%(1)$ & $0 \%(0)$ & $4.8 \%(1)$ & \\
\hline & Clinical Psychologist & $0 \%(0)$ & $0 \%(0)$ & $0 \%(0)$ & \\
\hline \multirow{2}{*}{$\begin{array}{l}\text { Interdisciplinary meetings for the sharing of clinical } \\
\text { decision-making }\end{array}$} & Performing & $17.2 \%(10)$ & $21.6 \%(8)$ & $9.5 \%(2)$ & \\
\hline & Not performing & $82.8 \%(48)$ & $78.4 \%(29)$ & $90.5 \%(19)$ & \\
\hline \multirow[t]{7}{*}{ Conference members } & OT & $15.5 \%(9)$ & $21.6 \%(8)$ & $4.8 \%(1)$ & \\
\hline & Nurse (NICU) & $13.8 \%(8)$ & $21.6 \%(8)$ & $0 \%(0)$ & $0.041^{*}$ \\
\hline & Rehabilitation physician & $12.1 \%(7)$ & $16.2 \%(6)$ & $4.8 \%(1)$ & \\
\hline & Pediatrician & $10.3 \%(6)$ & $16.2 \%(6)$ & $0 \%(0)$ & \\
\hline & SLT & $3.4 \%(2)$ & $5.4 \%(2)$ & $0 \%(0)$ & \\
\hline & Clinical Psychologist & $1.7 \%(1)$ & $2.7 \%(1)$ & $0 \%(0)$ & \\
\hline & Social worker & $0 \%(0)$ & $0 \%(0)$ & $0 \%(0)$ & \\
\hline \multirow[t]{2}{*}{ Parent education } & Performing & $63.8 \%(37)$ & $59.5 \%(22)$ & $71.4 \%(15)$ & \\
\hline & Not performing & $36.2 \%(21)$ & $40.5 \%(15)$ & $28.6 \%(6)$ & \\
\hline \multirow[t]{4}{*}{ Types of parent education } & $1: 1$ in-person education & $58.6 \%(34)$ & $59.5 \%(22)$ & $57.1 \%(12)$ & \\
\hline & Collective training & $8.6 \%(5)$ & $5.4 \%(2)$ & $14.3 \%(3)$ & \\
\hline & Distribution of educational documents & $5.2 \%(3)$ & $5.4 \%(2)$ & $4.8 \%(1)$ & \\
\hline & Distribution of educational videos & $5.2 \%(3)$ & $5.4 \%(2)$ & $4.8 \%(1)$ & \\
\hline
\end{tabular}

Non continuity variables are expressed ratio(frequency).

NICU: neonatal intensive care unit, OT: Occupational therapist, SLT: Speech-language therapist.

${ }^{*} p=<0.05$. 
Table 5. Limitations of current neonatal PT and suggestions

\begin{tabular}{|c|c|c|c|c|}
\hline Question & Answer & $\begin{array}{c}\text { Total } \\
(n=74)\end{array}$ & $\begin{array}{l}\text { Tertiary } \\
(n=39)\end{array}$ & $\begin{array}{l}\text { General } \\
(n=35)\end{array}$ \\
\hline \multirow[t]{4}{*}{ Barriers preventing the promotion of neonatal PT } & Insufficient awareness of colleagues & $48.6 \%(36)$ & $48.7 \%(19)$ & $48.6 \%(17)$ \\
\hline & Severity of the patient & $28.4 \%(21)$ & $33.3 \%(13)$ & $22.9 \%(8)$ \\
\hline & Insufficient awareness of parents & $9.5 \%(7)$ & $10.3 \%(4)$ & $8.6 \%(3)$ \\
\hline & Specialised skills required & $5.4 \%(4)$ & $5.1 \%(2)$ & $5.7 \%(2)$ \\
\hline \multirow[t]{3}{*}{ Necessities to promate neonatal PT } & Awareness of needs by colleagues & $62.2 \%(46)$ & $51.3 \%(20)$ & $74.3 \%(26)$ \\
\hline & Awareness of needs by parents & $35.1 \%(26)$ & $30.8 \%(12)$ & $40.0 \%(14)$ \\
\hline & Professional training program & $35.1 \%(26)$ & $33.3 \%(13)$ & $37.1 \%(13)$ \\
\hline \multirow[t]{2}{*}{ Do you have plans to promote neonatal PT? } & Yes & $43.3 \%(32)$ & $38.5 \%(15)$ & $48.6 \%(17)$ \\
\hline & No & $56.8 \%(42)$ & $61.5 \%(24)$ & $51.4 \%(18)$ \\
\hline \multirow[t]{3}{*}{ Optimal direction of neonatal PT } & Full-time physical therapists in NICU & $51.4 \%(38)$ & $48.4 \%(19)$ & $54.3 \%(19)$ \\
\hline & Visit when referred to a neonatal physical therapy & $47.3 \%(35)$ & $51.3 \%(20)$ & $42.9 \%(15)$ \\
\hline & Neonatal physical therapy is not necessary & $1.4 \%(1)$ & $0 \%(0)$ & $2.9 \%(1)$ \\
\hline
\end{tabular}

Non continuity variables are expressed ratio (frequency).

NICU: neonatal intensive care unit, PT: Physical therapy or Physical therapist.

they have no such plan. Nevertheless, the participants stated that the optimal direction of neonatal PT would be to have a full-time physical therapist available in the NICU to provide intensive care.

\section{DISCUSSION}

This study aimed to identify the roles of physical therapists who provide interventions for critically ill neonates and present suggestions for making advances in neonatal PT in Korea by examining the current status of neonatal PT in Korea. Our survey revealed that as of 2019, 74 out of 92 healthcare facilities (39 tertiary and 35 general hospitals) with a NICU nationwide run a pediatric physical therapy unit. Of these hospitals, 58 (78.38\%) hospitals performed neonatal PT, and this percentage significantly differed between tertiary hospitals (94.9\%, 37 hospitals) and general hospitals (60\%, 21 hospitals).

Neonatal PT is an advanced field of pediatric PT and continuous advances are being made. ${ }^{9}$ Therefore, physical therapists in this field are required to have high levels of experience and academic competence. The majority (63.5\%) of the neonatal physical therapists in our study had more than 7 years of experience. In a Canadian study, a high percentage (64.3\%) of neonatal physical therapists had at least 10 years of experience, and the percentage of experienced physical therapists was similar to that in Korea. ${ }^{11}$ It is promising that a high percentage of physical therapists in the field of neonatal intensive care, which involves high risks, is knowledgeable and experienced.
In Korea, more than half of the practitioners had a master's degree or higher (51.4\%). An Australian study also reported that the percentage of highly educated physical therapists with a master's degree or higher is particularly high among professions involved in the NICU. ${ }^{10}$ As the field of neonatal intensive care also requires advanced knowledge, the high percentage of highly educated practitioners is also promising and should be further enhanced. On the other hand, considering that the majority of hospitals with an NICU in Korea only have a single therapist in charge of neonatal PT (55.2\%), allocate less than 5 hours a week for neonatal PT (89.7\%), and treat fewer than 5 patients a week (81\%), it is currently difficult to fully commit to the practice of neonatal PT. This suggests that despite the fact that physical therapists are experts in physical function and sensorimotor development, their scope of work is still limited, with low levels of access to NICUs. ${ }^{13}$

In regard to the allocation of neonatal PT related work in Korea, there was a difference in the duration of neonatal PT (per session) according to hospital size (between tertiary and general hospitals), where the most common duration per neonatal PT session was "less than 10 minutes" (57.1\%) in general hospitals and "less than 20 minutes" (43.3\%) in tertiary hospitals. Neonatal PT, which is performed by visiting the NICU, is claimed as "simple therapeutic exercise" for payment in Korea. The criteria for this fee include performing the therapy for " 10 minutes or longer," and this code is applied to treatments such as range of motion exercises. General hospitals, or their equivalents, seem to have designated the duration of treatment to 10 
minutes or less based on the criteria for this fee. Tertiary hospitals submit a variety of claims in addition to simple therapeutic exercise, such as respiratory rehabilitation and central nervous developmental rehabilitation, depending on the clinical symptoms of critically ill neonates, which suggests that they allocate more time for neonatal PT,

A Canadian study reported that the use of a standardized evaluation form for neonatal PT has increased in recent years. ${ }^{11}$ In Korea, $50 \%$ of physical therapists used a form developed by their hospital, while 50\% did not perform an evaluation at all. An unstandardized evaluation cannot be used as reference and baseline data for treatment planning is obsolete when the patient is transferred to another hospital. A lack of corresponding fee for diagnostic evaluation hinders the allocation of time for the practice in a clinical setting. There are diverse demands for the growing practice of PT in the field of rehabilitation. The current medical fee criteria limit PT practice and thus hinders meeting the mixed needs among patients. As indicated by the responses in tertiary hospitals, a claim fee schedule that is commensurate with diverse clinical symptoms in patients must be established to facilitate well-contextualized advances in the discipline of PT for critically ill patients.

Neonatal rehabilitation teams generally comprise physicians, nurses, physical therapists, occupational therapists, and speech therapists. ${ }^{7}$ In Korea, a rehabilitation physician (75.9\%), pediatrician (67.2\%), NICU nurse (58.6\%), occupational therapist (50\%), and speech therapist (3.4\%) generally form a team for the PT of critically ill neonates. Whereas dysphagia in critically ill neonates is intervened by occupational therapists in Canada and Korea, this is generally considered an area handled by speech therapists in Australia and New Zealand, showing differences in the professional roles across countries. ${ }^{10,11}$

More diverse professionals were found to participate in the rehabilitation team for sharing clinical decision-making in tertiary hospitals than in general hospitals. Particularly, compared to that in general hospitals, there were significantly more responses in tertiary hospitals that decision-making is shared with NICU nurses. Amid restricted visiting by parents and an inability for a physical therapist to stay full-time in the NICU, nurses are the individuals who stay beside the infant 24 hours a day. In order to continue interventions, such as postural training and postural drainage, determined by physical therapists beyond the allotted time for PT, sharing deci- sion-making with nurses is crucial. In addition to decisions related to PT, all decisions made for a patient must be shared among all professions dealing with the patient so as to maintain the optimal state for survival and functional improvement.

While a family centered approach is strongly emphasized in Canada, only $63.8 \%$ of hospitals were found to give parental education in Korea. The type of education commonly applied was 1:1 in-person education. Distributing educational brochures for parents who discharge the NICU can increase the satisfaction of neonatal physical therapy. ${ }^{14}$ Neonatal physical therapists should consider how to apply the educational program of neonatal physical therapy more parent-friendly to improve the quality of the educational program. As preterm birth and low birth weight are risk factors for slow growth and developmental delay in infancy, these infants are generally subject to periodic follow-ups in an outpatient setting. ${ }^{15}$ Parents are considered the core of pediatric rehabilitation ${ }^{16}$ and practical scientific evidence demonstrating the significance of family-centered treatment has being reported. ${ }^{17}$ Family participation in the decision-making process for neonatal rehabilitation is important, as it aids therapeutic decision-making by experts such as physical therapists and boosts parents' confidence in parenting and competence. ${ }^{2,18,19}$ Parental education must be expanded through a familycentered approach in order to foster an environment that continuously promotes normal development of preterm and low birth weight infants.

This study is the first report of the current practice of neonatal PT in Korea. Although the roles and scope of work for physical therapists vary across countries equipped with a NICU system, there is a consensus on the need for a standardized scale for the evaluation and intervention performed by physical therapists in the NICU, and studies examining the current state of affairs and aiming to present measures for the improvement and implementation are actively ongoing. Neonatal physical therapists in Korea should strive to increase the awareness of the need for PT in the NICU among various healthcare professionals and parents of infants, and studies should also establish evidence for neonatal PT based on both standardized assessments and interventions. We hope that the findings of this study serve as basic data to review the current status of neonatal PT and to further advance neonatal PT in Korea. 


\section{ACKNOWLEDGEMENTS}

Thank you to all the physical therapists working in the field of neonatal physiotherapy in Korea. And thank you very much for answering this questionnaire. The development of neonatal physical therapy in Korea is due to your dedication. This research was conducted as a purely academic research without any financial and technical support.

\section{REFERENCES}

1. Kim S, Savage TA, Song MK et al. Nurses' roles and challenges in providing end-of-life care in neonatal intensive care units in South Korea. Appl Nurs Res. Published online 2019;50:151204.

2. Byrne E, Campbell SK. Physical therapy observation and assessment in the neonatal intensive care unit. Phys Occup Ther Pediatr. 2013;33(1):39-74.

3. Byrne E, Garber J. Physical therapy intervention in the neonatal intensive care unit. Phys Occup Ther Pediatr. 2013;33(1):75-110.

4. Shim JW, Jin HS, Bae CW. Changes in survival rate for very-low-birthweight infants in Korea: comparison with other countries. J Korean Med Sci. 2015;30(Suppl 1):S25-S34.

5. Seaton SE, King S, Manktelow BN et al. Babies born at the threshold of viability: changes in survival and workload over 20 years. Arch Dis Child Educ Pract Ed. 2013;98(1):F15-F20.

6. Healthcare Bigdata Hub. Annual statistics from 2010 to 2018 of code R62 (other lack of expected normal physiological development). Health Insurance Review \& Assessment Service (HIRA). http://opendata.hira. or.kr/op/opc/olap3thDsInfo.do

7. Limperopoulos C, Majnemer A. The role of rehabilitation specialists in Canadian NICUs: a national survey. Phys Occup Ther Pediatr. 2002;
22(1):57-72.

8. Sweeney JK, Heriza CB, Reilly MA et al. Practice guidelines for the physical therapist in the neonatal intensive care unit (NICU). Pediatr Phys Ther. 1999;11(3):119-32.

9. Sweeney JK, Heriza CB, Blanchard Y. Neonatal physical therapy. Part I: clinical competencies and neonatal intensive care unit clinical training models. Pediatr Phys Ther. 2009;21(4):296-307.

10. Allinson LG, Doyle LW, Denehy L et al. Survey of neurodevelopmental allied health teams in Australian and New Zealand neonatal nurseries: staff profile and standardised neurobehavioural/neurological assessment. J Paediatr Child Health. 2017;53(6):578-84.

11. Borges Nery P, Snider L, Camelo JS et al. The Role of Rehabilitation Specialists in Canadian NICUs: a 21st Century Perspective. Phys Occup Ther Pediatr. 2019;39(1):33-47.

12. Kim SM, Park SH, An SJ. Current Status of Occupational Therapy in Korean University Hospital NICUs. KSIM. 2014;2(4):19-27.

13. Altimier L, Phillips RM. The neonatal integrative developmental care model: seven neuroprotective core measures for family-centered developmental care. Newborn Infant Nurs Rev. 2013;13(1):9-22.

14. Lee HY, Kang DY. Effects of positioning education program through oral explanations or brochures for parents of premature infants with brain lesions and the satisfaction level of physical therapy at discharge. J Kor Phys Ther. 2017:29(5):259-64.

15. Walker SP, Wachs TD, Gardner JM et al. Child development: risk factors for adverse outcomes in developing countries. Lancet. 2007; 369(9556): 145-57.

16. Barbosa VM. Teamwork in the neonatal intensive care unit. Phys Occup Ther Pediatr. 2013;33(1):5-26.

17. Arango P. Family-centered care. Acad Pediatr. 2011;11(2):97.

18. Garber J. Oral-motor function and feeding intervention. Phys Occup Ther Pediatr. 2013;33(1):111-38.

19. Goldstein LA. Family support and education. Phys Occup Ther Pediatr. 2013;33(1):139-61. 